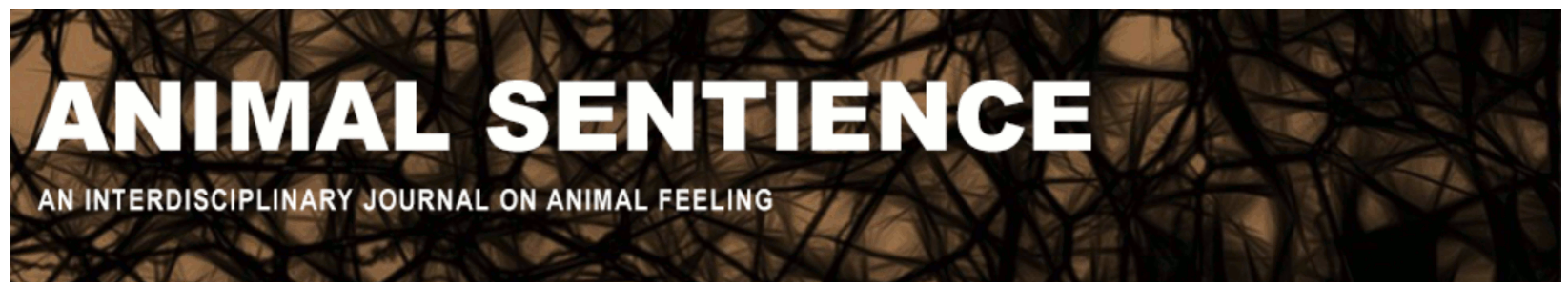

Peña-Guzmán, David M. (2018) Can nondolphins commit suicide?. Animal Sentience 20(20)

DOI: $10.51291 / 2377-7478.1327$

Date of submission: 2018-05-17

Date of acceptance: $2018-08-20$

(c)

This article has appeared in the journal Animal

Sentience, a peer-reviewed journal on animal

cognition and feeling. It has been made open access,

free for all, by WellBeing International and deposited

in the WBI Studies Repository. For more information,

please contact

wbisr-info@wellbeingintl.org.

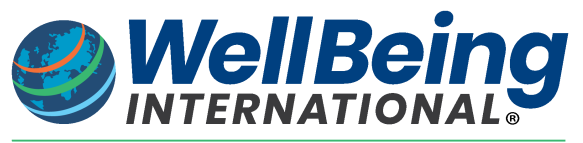

SOLUTIONS FOR PEOPLE, ANIMALS AND ENVIRONMENT 


\title{
Can nondolphins commit suicide?
}

Response to Commentary on Peña-Guzmán on Animal Suicide

\author{
David M. Peña-Guzmán \\ School of Humanities and Liberal Studies \\ San Francisco State University
}

\begin{abstract}
This Response addresses the scientific and philosophical criticisms of my 2017 target article "Can nonhuman animals commit suicide?" It defends my key claims and explores topics (such as animal judgment, animal theory of mind, and the evolution of suicide) that did not appear in the original article. It also points out areas in which further research is needed and concludes that we should be wary of accusations of "anthropomorphism" in debates about animal suicide.
\end{abstract}

David M. Peña-Guzmán is Assistant Professor in Humanities and Liberal Studies at San Francisco State University. He holds a Ph.D. in Philosophy from Emory University. His interests include animal cognition and behavior, the history and philosophy of science, continental philosophy, and social theory. Website

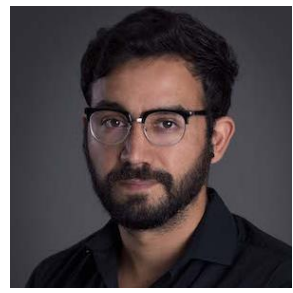

I would like to thank the commentators for taking the time to read and respond to my target article (Peña-Guzmán 2017) and for articulating important critiques of my position on animal suicide. Some of these made me rethink some of the claims I made in the article ${ }^{1}$; others afforded me the opportunity to further clarify and defend my argument; ${ }^{2}$ and others pushed me to confront issues I had not yet considered but now view as germane to the subject. ${ }^{3}$ Here, I respond to these critiques and defend my original claim that "there are sound empirical and philosophical reasons to support the animal suicide hypothesis" (p. 18).

In section 1 (What Is Suicide?), I talk about definitions. How should we define suicide? Much hangs on this deceptively simple question since the definition we choose will determine whether animals can fall under its scope. In section 2 (What Makes Us So Special (and Suicidal)?), I discuss three capacities that some commentators believe are exclusively human and justify an anthropocentric theory of suicide: intent, judgment, and theory of mind (ToM). In section 3 (The Evolution of Suicide), I discuss the evolution of suicide. While I do not take a definitive stance, I catalogue some of the views presented and respond to those that employ evolutionary arguments of various sorts to support the anthropocentric position. Then, in section 4 (Areas for Further Research), I discuss four areas where further research may help: (i) empirical work on the self-destructive behaviors of animals, (ii) interdisciplinary work on animal emotions, (iii) work on animal ethics, and (iv) philosophical work on animality. I conclude in section 5 (Concluding Remarks) with some reflections about the respective

\footnotetext{
1 This includes Soper \& Shackleford's observation that scorpions cannot sting themselves and Ristau's warning about interpreting animal behavior as "ritualistic."

2 This is true of Eilam's and Hadley's comments about intention and judgment.

${ }^{3}$ This applies to commentaries that discussed the evolution of suicide (Preti, Racine, deCatanzaro, and Soper \& Shackelford) and the philosophy of existence (Kuperus and Hediger), and those that offered suggestions for further research (Lester and Jensvold).
} 
dangers of anthropomorphism and anthropodenial in scientific debates about animal sentience, cognition, and behavior.

\section{What Is Suicide?}

Most of us have no problem conjuring up clear cases of suicide. Yet, for every easy case there seem to be twice as many hard ones about which perfectly reasonable people disagree. ${ }^{4}$ Consider the following hard cases:

- Should my decision to hasten my death if I have an incurable disease count as suicide?

- What if I refuse to eat food or drink water for political or religious reasons and die as result?5

- Is dying from grief suicide? ${ }^{6}$

- Is dying in a kamikaze mission or a suicide bombing suicide?7

- Is it suicide if I, knowing this is likely to end in my death, point a gun at a police officer?

- What if my battalion is about to be massacred and I leave my hiding spot to defend it even though I know that I, too, will die in the slaughter?

- And what about "honor suicides," such as the old Indian practice of suttee in which women were expected to self-immolate on their husbands' pyre - are they really suicides given that they were culturally compelled?

Our intuitions about these cases diverge because suicide is an extremely complex phenomenon. On the one hand, each suicide is opaque and we can never claim to fully understand it. On the other, suicides as a class are astonishingly diverse in the sense that many suicides don't seem to have much in common with one another.

The opacity of the One and the diversity of the Many frustrate our attempts to define suicide and pin down its necessary and sufficient conditions. Those who try quickly realize that most definitions work well for some but not all cases. Some then react to this realization by losing themselves in a sea of analytic distinctions whose objective is to save the definitions rather than the phenomena. ${ }^{8}$ Unfortunately, these analytic maneuvers, which sometimes amount to little more than piling epicycles upon epicycles, never quite succeed in capturing all - only the cases researchers want to capture. It is almost as if the more tightly experts try to grasp the phenomenon, the more it slips between theirs fingers: as if the more they try to corral it into a neat set of conditions, the more opaque and diverse suicide becomes.

The commentaries on my target article demonstrate the colossal difficulty of reaching definitional consensus. Hadley, for example, defines suicide in terms of anguish, which excludes cases that do not involve anguish (e.g., suicide bombers). Eilam incorporates mental time-travel into his definition of suicide, but explicitly excludes grief-related deaths. Both of them describe suicide as intentionally choosing to die (which makes suicide dependent on

\footnotetext{
${ }^{4}$ Den Hartogh (2016) notes that we disagree even about the easiest case: "rational suicide." This happens when someone in full possession of their mental faculties and not in a state of anguish makes arrangements for death. Rational suicides "tend not to be registered as suicides at all."

${ }^{5}$ Velazquez (1987) says the answer varies.

${ }^{6}$ Benvenuti says yes. Eilam says no.

${ }^{7}$ It is for Preti, but not for Hadley.

${ }^{8}$ Common distinctions in the literature include: real vs. apparent suicide, suicidal attempt vs. suicidal completion, intended vs. unintended completion, motivated vs. unmotivated attempts, serious vs. trivial attempts, suicidal attempts vs. suicidal gestures, suicides vs. parasuicides, among others.
} 
rationality, choice, and intentionality). But, as Pierce observes, we can also describe suicide as losing the will to live, a description that is gaining favor in animal hospice and palliative care contexts (and which does not tie suicide to rationality, choice, and intentionality). In light of so much disagreement, it is no surprise that some suicide researchers have moved in the exact opposite direction and opted to forgo definitions altogether (Hawton \& Van Heeringen 2000, pp. 319-325).

Science, of course, needs definitions. But Jensvold is right that too much emphasis on definitions can lead us into futile semantic squabbles. And the danger is particularly high in the animal sciences. If we worry too much about what to call different animal behaviors, we can miss the behaviors themselves. So, instead of expecting the behaviors of animals to fit neatly into our ready-made categories, we should study these behaviors with the knowledge that we may have to tweak our categories as we go along. When we don't give ourselves this flexibility, we end up ordering the world around our concepts rather than ordering our concepts around the world. Thus, like Jensvold, I propose we settle for elastic and operational definitions that can be stretched in light of new findings rather than static and a priori definitions. Nature, after all, does not give a hoot about human dictionaries. ${ }^{9}$

In this spirit, I defined suicide in the original article as a continuum of self-directed and injurious behaviors that can seriously endanger or terminate the life-activity of an organism. Three aspects of this definition are worth accentuating:

(i) it defines suicide behaviorally, i.e., in terms of observable behaviors rather than unobservable mental states

(ii) it does not require, but also does not reject, conscious intent, and

(iii) it does not limit suicide to humans.

I do not advocate this leap from the mental to the behavioral because I embrace the tenets of classical behaviorism (à la Skinner) but because I have serious meta-methodological reservations about what it means to study nonhuman behavior. One of these is that we (we, humans) often assume that only we are intentional beings without ever reflecting on what might possibly count as evidence of intentionality in other species.

Baum puts his finger on this meta-methodological problem with a clever thought experiment, which I adapt and express in paraphrase here:

Imagine for a moment that you are not a human being looking at the self-destructive behaviors of a dolphin, but rather a dolphin looking at the self-destructive behaviors of a human. What will you, a member of the Delphinidae family, say about the selfdestructive behaviors of Homo sapiens? Will you say that Homo sapiens just harm themselves or that they commit suicide?

The answer, it turns out, will depend on the kind of dolphin you are. If you are the kind of dolphin that demands direct evidence of intentionality in other species before you accept that they are capable of suicide, you will conclude that nondolphins cannot commit suicide. Why? Because, as a dolphin, you presumably live and interact regularly with other dolphins, whom you naturally view as intentional beings. But, as a dolphin, you also look at the world through

${ }^{9}$ De Waal (2016) argues that too much emphasis on definitions is often a symptom of anthropocentrism (p. 157). 
a uniquely delphinic point of view, as only a dolphin can. You cannot access nondolphin experience or extract linguistic reports from nondolphins about the contents of their experience. Simply put, you have zero direct evidence of nondolphin intentionality because don't know "what it is like" to be a nondolphin. So, when asked whether nondolphins commit suicide, you conclude, "Absolutely not." But this conclusion, obvious as it may seem to you, will be mistaken. But you, a dolphin, will not see this error as long as you demand direct evidence of nondolphin suicide (which, by nature, you cannot have).

To avoid this false belief from the outset you will have to change your whole outlook: you will have to adopt a behavioral rather than a mentalistic approach to the issue since the mentalistic one, given the inescapability of your own delphinic cognitive apparatus, is already a trap. You will also have to accept indirect evidence of nondolphin suicide and recognize the limits of your dolphin-centric worldview, not to mention abstain from Delphinidae-centric definitions of suicide (that define it, say, in terms of voluntary breathing). In short, you will have to be the kind of dolphin that takes behavioral parallels between dolphins and nondolphins seriously and is willing, at least in principle, to revise his or her beliefs in light of new findings. My article encourages us to be this kind of dolphin (a sentence I never thought I'd write).

Notice that Baum's thought experiment does not turn on the empirical question of whether we can, to quote the fictional Elizabeth Costello, "think ourselves into the being of another" (Coetzee 1999, p. 35) - in this case a dolphin. Rather, it turns on the metamethodological insight that absence of direct evidence is not direct evidence of absence because when it comes to intentionality in other species, the notion of evidence is itself in question. When debating whether other species can commit suicide, we cannot assume from the get-go that they are not intentional. What we need to do is be cognizant of the limits of our own species-specific perspective and, to the extent that this is humanly possible, try to view things from another angle. Basically, we need to put ourselves (conceptually) in the shoes of an extra-terrestrial:

“What if, instead of looking at dolphins' self-injurious behavior and likening it to human behavior, we imagine what a dolphin might say when looking at human self-injurious behavior. Better yet, suppose a Martian were looking at both human and dolphin selfinjurious behavior. This nonhuman would observe that human creatures and dolphins usually avoid harm to themselves, but sometimes engage in self-injurious behavior, sometimes even to the point of death. Lethal self-injurious behavior would be seen as a subcategory of the more general category" (Baum, p. 2)

The Martian's definition is my definition. For me, as for Baum's Martian, suicide is an interspecies continuum of self-destructive behaviors, some of which culminate in death.

\section{What Makes Us So Special (and Suicidal)?}

My core argument is that there is no "special something" that makes us, and only us, capable of suicide. Numerous commentators, however, argue that such a magical ingredient exists and, at various points, nominate three different candidates: conscious intent, judgment, and theory of mind (ToM). 
Conscious Intent. The single most common concern critics express is that I exclude intentionality from my definition of suicide. "The intention to die," says Preti, "is central in the definition of suicide in humans." For a number of reasons, however, my theory is not based on the concept of intent.

First, intentions are inaccessible to empirical investigation. It is impossible to know when a particular intention is present or absent. This is true of the intentions of other people and our own. We all like to think that there is a reason behind our actions and that we have unequivocal first-hand access to them through introspection. But research in psychology, cognitive science, and neurobiology shows that a great deal of human behavior is brought about by unconscious processes of which we are largely unaware. These processes, which include implicit biases, emotional and affective states, unconscious desires, and ingrained habits, shape our behavior without our knowledge and render suspect our quotidian faith in the rational and intentional character of our actions. ${ }^{10}$ According to Benvenuti, "it is now widely recognized that cognitive, affective, and behavioral processes often unfold unconsciously and that this unconscious processing frees up limited processing resources."11 These processes throw a wrench in the folk-psychological belief that we always know why we do what we do. They demonstrate the degree to which we are, to quote Kristeva (1991), "strangers to ourselves."

Second, there are two ways to think about intentions. They can be mental states that exist alongside behavior (the weak version) or mental states that cause behavior (strong version). Those who define suicide in terms of a particular intuition (like the intent to die) must specify whether this intention needs to be present at the moment of death or whether it also needs to be the cause of suicidal action. For my death to count as suicide, is it enough for me to intend to die and then die, or do I have to die because I intended to die? Semantically, the difference is almost negligible. Conceptually, it is enormous. Entire classes of self-killings - e.g., kamikaze suicides and what Preti (2006) dubs "suicides with a hostile intent" - may or may not count as suicides depending on which version we embrace.

Third and finally, intentions do not always cause behavior. In the target article, I cited neuroscientific, phenomenological, and philosophical theories of action - especially Merleau-Ponty (2012), Searle (1983), and Libet (1999) - that decouple intention from action. These theories show "there are real cases in which intent appears either at the same time as (in actu) or even after (ex-post facto) the behavior it supposedly causes" (PeñaGuzmán 2017, p. 14). These theories turn the epistemological problem discussed above into an ontological one. It is not just that we cannot know when an intention is present or absent. It is that intentions, even if they are present and accessible, may be epiphenomenal. They may not precede the behavior they are thought to explain. If so, explaining a suicide by pointing to a particular intention may be epistemologically on par with explaining rain by pointing to the wetness of the streets. ${ }^{12}$

\footnotetext{
${ }^{10}$ In cases of suicide, the problem of self-knowledge is compounded by the fact that suicidal agents are often in the throes of mental illness, substance abuse problems, and psychopathologies of various kinds.

${ }^{11}$ Benvenuti cites Antonio Damasio, who places unconscious affects and emotions (rather than rational beliefs and conscious intentions) at the root of our cognitive life. Damasio's "affective neuroscience" has contributed to the "return of the unconscious" in contemporary neuroscience (Franks 2003).

12 Only Racine engages my critiques of intentionality. Yet, the position he develops is puzzling. Essentially, he says we should keep intent at the center of suicidal theories even if suicidal intent forms after the onset of
} 
The idea that suicides could exist that do not involve a conscious intent to die is not a purely logical possibility. Lester uses "victim-perpetrated suicide," which occurs when an individual wishes to die but is not actually conscious of this wish, as a candidate for unintentional suicide. In these cases, "it may be possible to conceptualize the [victim's] behavior as suicidal even though the deceased had no conscious suicidal impulses." In support of this claim, he cites the research of the American psychiatrist Karl Menninger (1938), who argues that "unconscious and self-destructive desires" motivate some suicides. In Man Against Himself (1938), Menninger warns against reducing all suicides to something as simplistic as the conscious intent to die.

"Paradoxically, many suicides in spite of the violence of the attack upon themselves do not seem to be very eager to die. Every hospital interne [sic] has labored in the emergency ward with would-be suicides, who beg him to save their lives. The fact that dying and being murdered achieve the same end so far as personal extinction is concerned, leads the practical-minded individuals to think, 'If a person wants to murder himself, or if he feels he is willing to be murdered, then he surely must want to die.' But the illustration just given is only one of many indications that this is not so.... In attempted suicide the wish to die may or may not be present or may be present to a quite variable degree" (Menninger 1938, p. 23).

In this passage, Menninger finds himself in the company of Émile Durkheim (1897), who asserts in Le Suicide that not all people who commit suicide actually wish to die. He mentions soldiers who run into battle to save their regiment while knowing this will result in their death, martyrs who die for the tenets of their faith, and mothers who sacrifice themselves for their children. Baum adds suicide by police to this list. All these suicides prove that conscious intent "need not be a component of all suicide explanations" (Peña-Guzmán 2017, p. 15).

I never meant to imply that intent is a worthless concept. On this point, I probably wasn't as clear as I should have been. Ristau, as a result, argues that I am "of two minds" about it: on the one hand, I dismiss it as an explanatory aid in suicide research; on the other, I defend my position by claiming that some animals "sustain intentions," which presupposes that intent matters. But this contradiction is only apparent. What I dismiss is not intent per se (although I do think it begets theoretical complications), but intent conceived as a necessary condition for suicide. Intent can be a useful heuristic in many cases, especially when cognitively sophisticated organisms (such as primates, cetaceans, and elephants) are involved. I agree it would be hard to make sense of some suicides, such as the suicide of the Vietnamese monk Thích Quảng Đức, without considering the mental states of the protagonists - their intentions, beliefs, and desires. But this does not mean that we need this concept every single time. For example, I also agree it would be hard to make sense of some suicides without invoking alcoholism, depression, or brain trauma as causes, but this does not mean that alcoholism, depression, or brain trauma are necessary conditions for suicide as a whole. The same, for me, is true of intent. Here, we need to watch out for the mereological fallacy (from the Greek méros meaning "part" + logos meaning "study"), which occurs when we conflate what is true of the part with what is true of the whole.

suicidal behavior. But why keep this concept if it does not explain the behavior in question? This conception of intent has no explanatory value as intentions could not reasonably be construed as causes. 
Mikhalevich, however, is unconvinced that a theory of suicide can work without intentionality. By getting rid of intent, she says, I pack too much into the category of suicide and end up grouping together behaviors with "radically different causal histories and ecological significance."13 She highlights the dangers of this tactic using an analogy of rape. When we talk about rape, we must not group together behaviors that seem similar but are actually very different. We must be especially vigilant of adaptationist accounts of rape that put rape on a continuum with other sex-related behaviors in humans and nonhuman animals. Such adaptationist narratives pass over "the social and psychological context in which most rapes occur, including the non-sexual motivations of many rapists," effectively "naturalizing" rape.

I agree with Mikhalevich about rape, but not about suicide. Rape, on my view (and, I assume, hers) is about power, not sex; and evolutionary accounts that "biologize" it are harmful. But why do we agree about rape? Because we agree that all rapes originate in the perpetrator's desire to dominate another, i.e., because we agree that all rapes share a common underlying etiology. This is exactly what I don't concede about suicide. Suicides do not have a common underlying etiology. Different suicides have "radically different causal histories" that involve causal factors such as alcoholism, depression, SSRIs, existential angst, drug addiction, moments of insanity, social exclusion, intent to harm others, loss of the will to live, delusions, and more. If anything, it is Mikhalevich herself who groups dissimilar things together with this rape analogy since rape and suicide are not analogous in the relevant way. I can accept an intentional interpretation of rape in which what matters are the non-sexual motivations of perpetrators, but this does not mean I must also accept an intentional interpretation of suicide. I can be a causal pluralist about suicide but not about rape. In order for her observation that I group together behaviors with different etiologies to pack a punch, Mikhalevich would have to defend the claim that all suicides do share an underlying etiology, which she has yet to do. ${ }^{14}$

Judgment. Hadley defends the anthropocentric conception of suicide using the concept of judgment. Even if many nonhuman animals are cognitively complex, he says, only humans commit "run-of-the-mill-suicide" because only humans make judgments.

"I presuppose that to take one's life, in the relevant sense for a discussion of animal suicide, is for an individual to do so under conditions of anguish - after making a judgment that one's life is not worth living. It is the wherewithal for making such a judgment, in the absence of compelling empirical evidence to the contrary, that it is reasonable to believe animals lack" (Hadley, p. 1).

Hadley's position is that to commit suicide, a subject must be in a state of anguish. Then, after carefully and rationally considering her future prospects, she must judge her life as unworthy of being lived. When these conditions click into place, one has "run-of-the-mill-suicide." But

\footnotetext{
${ }^{13}$ Mikhalevich also accuses me of overestimating the degree to which "mind" is either exclusively human or widespread throughout nature. While I believe that mind is not exclusively human, the vast continuum I describe is a continuum of self-destructive behavior, not of mental capabilities.

${ }^{14}$ Mikhalevich calls for suicidologists to "parse out" the suicides of different species based on shared causal factors (such as intentions, social-ecological context, or evolutionary history), but suicidologists can't, and won't, do this if they don't first embrace some form of continuity.
} 
only humans can make these kinds of judgments which require having mental states with the appropriate content. I find Hadley's objection intriguing, but in the end unconvincing. Here, I respond to it on its own terms before questioning its underlying assumptions.

Sadly, Hadley never specifies what "content" he has in mind (no pun intended). Presumably, for run-of-the-mill suicide, an individual would need two capacities: (a) mental time travel capabilities (to imagine her future prospects) and (b) a sense of what, for them, constitutes a good life (to know that hers isn't it). Assuming this is true, I do not see why animals should be automatically excluded. There is ample evidence that animals can plan for the future in ways that "do not directly follow from present needs and desires" (de Waal 2016, p. 213) and have expectations about what the future holds. Experiments on expectancy and violation-of-expectation demonstrate that animals systematically express surprise when their expectations are not met (Lurz 2011, pp. 116-120, 180-184). Animals look to the future, consider it, and plan for it. Some of them, therefore, meet condition (a).

The trickier condition, of course, is (b). How could anyone believe, let alone prove, that animals have a sense of the good life? The key lies in what we mean by "having a sense of the good life." Consider the following syllogism:

Premise 1. Chimpanzees have a concept of "death."15

Premise 2. Chimpanzees have their own species-specific concepts of "good" and "bad" (or "better" and "worse"). ${ }^{16}$

Premise 3. Chimpanzees can make judgments by combining concepts and subsuming particulars under them. ${ }^{17}$

Conclusion. Chimpanzees may have a sense of what counts as a "good death" or a "bad death" (by combining the appropriate concepts), and they may prefer the former to the latter.

Now, as an exercise in formal logic, this syllogism may be all well and good. But do chimpanzees really prefer some deaths to others as a matter of fact? Do they really discriminate between good and bad deaths? Anderson et al. (2010) claim they do. Chimpanzees prefer to die "in communion with others" rather than by themselves (PeñaGuzmán 2017, p. 17, fn. 27). For them, a lonely death is a bad death.

If chimpanzees have a concept of death, they could also have a concept of life (although, to my knowledge, nobody has investigated the issue). If so, a version of the above syllogism could be constructed such that chimpanzees have a sense of what counts as a "good life" or a "bad life." If they prefer some deaths to others, why couldn't they also prefer some lives to others? If they prefer to die with the chimpanzee analog of dignity, why couldn't they also prefer not to live without it? I know I am entering speculative territory here, but the point is that it is not absurd to believe that some animals could meet Hadley's condition (b), such that we could meet Hadley's objection on its own terms (even if only in an exceedingly small number of cases).

\footnotetext{
${ }^{15}$ See Anderson et al. (2010).

${ }^{16}$ This is evidenced by the fact that chimpanzees have preferences and discriminate between things they like and dislike. Research in primatology has shown that nonhuman primates even have a sense of "right" and "wrong" (de Waal 2010; Brosnan 2013; Brosnan \& de Waal 2012), the moral equivalents of good and bad.

${ }^{17}$ This is a contentious claim, but chimpanzees can make judgments such as "Tommy is a good friend," "Grapes are a good food," "The tree in the yard is a bad sleeping spot," and "Peter is a cheater." See Glock (2010).
} 
But we may not need to meet Hadley's objection on its own terms since, on my view, its terms are problematic. To begin with, Hadley favors an excessively mentalistic understanding of judgment drawn from analytic philosophy of mind, according to which judgments are thoughts composed of concepts. But since thoughts are typically defined in this literature as having a propositional structure ( $"$ that $X$ "), this view of judgment ostensibly requires language, automatically excluding all nonhuman animals. The philosophical framework within which Hadley's objection operates, then, may itself be the problem.

In "Can Animals Judge?" the philosopher Hans-Johann Glock (2010) targets this framework and claims that instead of fretting over whether animals have the right kinds of mental states with the right kind of content for the formation of the right kinds of thoughts with the right kind of structure, we should simply look at how animals interact with their environment and decide whether it would make sense to ascribe certain thoughts (including judgments) to them (even if such thoughts could not possibly have a propositional form inside their minds) (p. 11). In the case of suicide, the self-injurious behaviors of animals may justify ascribing certain judgments to animals (e.g., "that life is not good" or "that life is not worth living") without having to prove that animals can sustain propositional attitudes as a matter of fact.

Putting this aside, another problem with Hadley's commentary is his definition. As noted above, he defines run-of-the-mill-suicide in terms of anguish and judgment. This excludes a number of suicides that suicide researchers may not want to exclude, including all human suicides not committed in a state of anguish (e.g., kamikaze suicides, suicide bombings, suicides motivated by religious and political convictions, and rational suicides) and all human suicides in which an explicit mental judgment about future prospects is missing (e.g., impulsive suicides, child suicides, and the suicides of people in the grip of addiction). What's more, Hadley never specifies whether run-of-the-mill suicide (as he understands it) is synonymous with suicide as a whole or denotes a special sub-class. Do nonrun-of-the-mill suicides exist, according to Hadley? I frankly cannot tell. Perhaps he thinks that run-of-the-mill suicides are the gold standard of suicide. That's fine. But this would not prove that animals cannot commit suicide. It would only prove that they don't commit runof-the-mill suicide. Maybe they just commit non-run-of-the-mill suicide, which would still be suicide. ${ }^{18}$

Theory of Mind. Racine contends that suicide depends on having a "theory of mind" (ToM), which only humans possess. This turn to ToM is unexpected since this concept does not play a major role in the suicide literature, and probably for good reason. The idea that suicide requires ToM capacities is at odds with the fact that there are humans who do not meet the requirements of most ToM theories, such as people living on the higher end of the autism spectrum, and who commit suicide nonetheless. ${ }^{19}$ This alone refutes Racine's claim that "human 'theory of mind' capacities might be required for behavior to be considered suicidal"

\footnotetext{
18 The terms grounding Hadley's definition, anguish and judgment, may also undermine one another. Perhaps the more I sink into a state of anguish, the less I am capable of making a rational judgment about my future prospects, and vice versa.

${ }^{19}$ By most accounts, autism prevents people from recognizing other people as having a mind of their own. People on the higher end of the spectrum fail the core requirement of virtually every ToM theory (Moran et al. 2011; Baron-Cohen 1997). Yet, they commit suicide — and in high numbers (Mayes et al. 2013; Dweerdt 2014).
} 
(p. 2). Even if this weren't so, we could flip the argument around since there is vast, and growing, literature showing that many animals display ToM-relevant capacities, such as deception, shared intentionality, targeted help, joint attention, teaching, and empathy (Wise 2000, pp. 194-217; Suddendorf \& Buby 2003; Zentall 2006).

In general, theories of ToM fall into two categories: low-expectation theories (LETs) and high-expectation theories (HETs). LETs define ToM as understanding that others have intentions. HETs are more demanding and define ToM as understanding that others have a mind and understanding "intentions in general" (i.e., having a concept of intention). Whether (and which) animals have ToM capacities will depend on whether we adopt a LET or a HET. Under most LETs, even pre-verbal infants have an implicit ToM (Gómez 1996; 2007). So, it is reasonable to assume that a good number of animals do too.

But Racine adopts a HET. According him, having a ToM requires viewing others as intentional beings and understanding intentions "in general." In support of this interpretation, he cites the work of Michael Tomasello, who argues that chimpanzees do not understand intentions "in general." Racine interprets this to mean that only humans understand intentions and thus are capable of suicide. Although I cannot offer a detailed critique of Tomasello's research program here, Racine ignores that this program, by Tomasello's own admission, only proves that chimpanzees cannot grasp communicative intentions, not that they do not understand basic intentions in general (Zlatev et al. 2013, p. 313). It also ignores Leavens, Bard, and Hopkins's (2017) claim that Tomasello's flawed methodology invalidates his conclusions.

\section{The Evolution of Suicide}

Although the original article does not deal with evolution, its continuity thesis operates within a broadly Darwinian framework. This prompted some commentators to inquire into the relationship between evolution and suicide. As there was no consensus about how (or even whether) suicide evolved by natural selection, in this section, I explain the various positions that surfaced while pinpointing problems with those that sought to rescue the anthropocentric theory of suicide with evolutionary hypotheses.

Racine claims that leading adaptationist explanations of suicide, such as deCatanzaro (1995) and Tanaka and Kinney (2001), do not support the continuity thesis. These theories may prove that suicidal behavior is "heritable in humans" and has "a potential adaptive function," but not that it is found in other species. "Although [adaptationist] hypotheses might capture something of the ancestral condition of anatomically modern humans," he writes, "they leave open the question of whether these explanations would automatically support the continuity thesis."

The idea, roughly, is that suicidal behavior emerged after modern-day humans split off from our closest evolutionary ancestors and is thus the exclusive evolutionary achievement of Homo sapiens.

Unfortunately, Racine's claim that leading adapationist theories do not support a continuist paradigm is simply false. DeCatanzaro (1995) and Tanaka and Kinney (2001) both allow for interspecies continuity. DeCatanzaro, whose sociobiological theory of suicide rests on inclusive fitness, believes that some animals can commit suicide, even if he limits this to big-brained creatures such as dolphins. Tanaka and Kinney (2001), who impute the adaptive value of suicide to the protection of kin from infectious diseases, allow suicidal behavior in 
other species, especially those "that live in complex social communities" (p. 986). Contemporary adaptationist theories of suicide, therefore, already accommodate the animal suicide hypothesis.

Preti, like Racine, defends this latecomer view of suicide and says that suicide appeared on the evolutionary scene only quite recently, after the development of agriculture. The advent of agriculture changed in radical ways how people lived and, among other things, brought about the collapse of kin-centric life by making individuals in agricultural societies live with people to whom they were not genetically related. By contrast, people in preagricultural societies lived in closely-knit kin-related groups similar to those found today in the wild among nonhuman mammals. Since agriculture, then, humans have become genetically isolated, "increasingly living in groups that are not as closely related genetically as social groups of nonhuman mammals." This isolation, Preti says, breeds suicide. Curiously, Preti does not necessarily grant that suicide "is under genetic control." What matters to him is that agriculture caused a breakdown in kin relations and that this breakdown made suicide possible either by producing psychopathologies that lead to suicide (in the version that does not require a genetic component) or by giving the gene or genes for suicidal behavior an adaptive value in this ancestral context (in the version that does). Either way, suicide is an example of evolutionary discontinuity.

But Preti's theory is open to some interpretation. If what ultimately leads to suicide is the breakdown of kin-centric living in social animals, any social animals that live in kinunrelated groups could be susceptible to suicide. This would not include wild animals living in kin-related groups, but it could include social animals trapped in laboratories, marine parks, farms, menageries, zoos, and aquaria, often in ethologically impoverished environments. Many of these animals suffer from the kinds of genetic isolation and interpersonal conflict that, in Preti's theory, snowball into suicide.

DeCatanzaro espouses this latter view. For him, individuals commit suicide when they battle "social isolation and a sense of rejection, burdensomeness, and shame." This battle is waged on two fronts: a biochemical front that produces feelings of dysphoria and despondency in socially unfit individuals, and a cognitive front that permits those same individuals (assuming they are capable of voluntary action) to act on those feelings. ${ }^{20}$ Although his is a theory of human suicide, deCatanzaro grants some animals, such as dolphins, could fall under it. Biochemically, dolphins display the right kind of "affective variation." They show clear signs of dysphoria and despondency, feelings that "clearly have deep roots in animal behavior and are not uniquely human." Cognitively, they demonstrate capacities of neo-cortical control, "which may allow insight into self and others, anticipation of consequences of complex actions, future planning, and flexible voluntary behavior." These capacities could enable them to override their self-preservation instincts vis-a-vis suicide.

On deCatanzaro's account, biological systems have self-preservation instincts, but these are "not necessarily unconditional." They can be overridden, a possibility Soper $\boldsymbol{\&}$ Shackelford find unacceptable. Suicide, they argue, could not have evolved in animals because there are powerful and inviolable mechanisms that protect animals from selfdestruction. "Suicide is not observed in nonhumans," they write, "for a straightforward

\footnotetext{
${ }^{20}$ For deCatanzaro, suicide can be adaptive when "individuals encounter a conjunction of poor reproductive prospects and burdensomeness towards kin" (p. 2). Suicide increases inclusive fitness by removing from the evolutionary space organisms that are a burden to the germ-line.
} 
reason: any genes that permitted suicide would have been eliminated along with the suicides' bodies." Of course, Soper \& Shackelford know that some animals do sacrifice their bodies, as happens with the self-destructive behaviors of hymenoptera. But they work around this in a somewhat bizarre manner. They dismiss these behaviors as irrelevant to the question of suicide on the grounds that the reproductive strategy of hymenoptera allows us to explain said behaviors in terms of kin selection, which proves they have nothing to do with suicide: "Many organisms sacrifice their soma according to algorithms of inclusive fitness: nonbreeding siblings in eusocial colonies - hymenopteran insects, for example — often die defending the colony; other organisms that breed only once have nothing to lose by dying once their reproductive work is done." The implication seems to be that if a species has the kind of reproductive strategy that allows evolutionary theorists to explain their selfdestructive behaviors according to principles of inclusive fitness, then those behaviors are not suicidal "in the meaningful sense of the word."

What is bizarre is that immediately after arguing that hymenoptera cannot commit suicide because they have a specific reproductive strategy, Soper \& Shackelford argue that dolphins cannot commit suicide because they don't have the same reproductive strategy as hymenoptera. The contradiction stems from the authors' lack of clarity about the relationship between suicidal behavior and inclusive fitness. On the one hand, they imply that acts of selfdestruction that enhance inclusive fitness are not suicides "in the meaningful sense of the term." 21 On the other hand, they seem to favor an adaptationist view of human suicide (possibly anchored in inclusive fitness?) since they also critique my article for lacking a "a coherent explanation as to how selection could favour and maintain such a capability [for suicide in animals]." In the same breath, then, they criticize me for not providing an adaptationist narrative while also claiming that such narratives would foreclose the possibility of talking about suicide meaningfully. It does not help that they never specify what suicide "in the meaningful sense of the term" actually means. ${ }^{22}$

\section{Areas for Further Research}

Based on the commentators' critiques and feedback, I have identified four areas for further research. Work in these areas may give us a better understanding of the relationship between animals and suicide.

Empirical Work on the Self-Destructive Behaviors of Animals. Some may believe that it is impossible to study animal suicide empirically because we cannot access the minds of nonhuman animals. Lester, however, invites us to envision empirical protocols that may bear

\footnotetext{
${ }^{21}$ Some theories explain human suicide in terms of inclusive fitness, such as deCatanzaro's (1995) and Tanaka and Kinney's (2001). If human suicide can be given an inclusive fitness explanation (like the self-killings of hymenoptera), Soper $\&$ Shackelford might be forced to conclude that humans also don't commit suicide "in the meaningful sense of the word."

22 They do say humans have crossed a "cognitive floor" that makes suicide possible. What this floor is, we do not know. All we know is that it happens "around puberty and involves 'conception."' What does conception entail? We also do not know. Either way, to make this floor hold up, Soper \& Shackelford would need to clarify six things: (1) what they mean by "conception," (2) whether it involves specific mental states and mental concepts (and which), (3) whether it needs to temporally precede the act, (4) whether all humans reach it or only neurotypical ones, (5) why we ought to assume that only humans reach it, and (6) whether it leaves room for evolutionary explanations rooted in inclusive fitness.
} 
directly on the question of whether animals can commit suicide. He uses Schaeffer (1967) as an example. Schaeffer claims that researchers can shed an empirical light on animal suicide by tackling three questions: "(1) Can the animal discriminate between life and death or, to be more specific, between a live animal and a dead animal? (2) Can an animal discriminate between a lethal and a nonlethal environment? (3) Under what circumstances will an animal choose to enter a lethal environment?"

In the 1960s, Schaeffer used an operant conditioning technique on laboratory mice to address these questions. In the protocol, mice were presented with two chambers: a lethal chamber in which the mice who entered would be brutally killed by electrocution and a nonlethal chamber in which the mice were left unharmed. Schaeffer wanted to see whether mice would detect the difference; he found that mice who observed other mice enter the lethal chamber and die subsequently avoided the chamber altogether. According to him, this suggests that mice discriminate between living and dead conspecifics and between lethal and nonlethal environments. This approach shows that animal suicide can be studied empirically (though one hopes it can be studied without hurting or killing animals or imprisoning them in laboratories).

Jensvold also makes a plea for further empirical research on suicidal behavior, but she uses comparative sign language studies as a model. She writes:

"The successes of sign language studies with cross-fostered chimpanzees came from treating them under comparable conditions and using the same measures of language acquisition in infant chimpanzees as the ones used in human children.... Similar methods can be applied to suicide. What behaviors constitute suicide? Which of these behaviors appear in humans? Which of them appear in nonhumans? Through clear operational definitions of behaviors and an understanding of Darwinian principles, we can come to understand what constitutes suicide and how it is manifested" (Jensvold, p. 2).

This is a valuable suggestion. While there are better and worse ways of studying language acquisition in nonhumans (Wise 2000, pp. 172-178), this field can teach us invaluable lessons about how to study animal behavior, such as the importance of beginning from behavior rather than a priori definitions, of recognizing that how humans do X need not be how other animals do $\mathrm{X}$, of being attentive to researcher bias, and of not reaching grand conclusions from negative findings.

Interdisciplinary Work on Animal Emotions. One of the virtues of the cognitive revolution in the study of human behavior was that it brought into sharp relief the importance of different kinds of mental states, including emotional ones. (For a critique of the cognitive revolution, see Thomas who advocates cataloguing the "psychochemical changes" in the central nervous system [CNS] instead of talking about mental states without distinct psychochemical CNS correlates).

While many scientists nowadays accept that emotions influence human behavior, skepticism about animal emotions abounds. The best way to combat this skepticism is by giving emotions, especially negative ones, a more prominent place in our list of research priorities (de Waal 2016, p. 273). But since all emotions have physiochemical, neurobiological, and psycho-social dimensions (Nussbaum 2003), this research has to go beyond Thomas's "CNS physiochemical substrates" and combine physiochemical, 
neurobiological, ethological, psychological, and even philosophical insights. If done correctly and ethically, this research could pay dividends to psychology, evolutionary cognition, animal behavior, neurobiology, affective neuroscience, and the philosophy of mind.

Recent work on "complicated grief" among animals illustrates the value of taking animal emotions seriously. Grief is a reaction to a devastating loss that triggers feelings of anxiety, guilt, sadness, and despair. As individuals comes to accept the irreversibility of their loss, these feelings gradually disappear until the individual forms new emotional attachments and returns to a normal or semi-normal life. Complicated grief works differently. Complicated grief is a reaction to loss in which individuals, for causes still unknown, cannot accept the loss and adjust to their new reality. They are in denial about the loss. ${ }^{23}$ While the literature on complicated grief has historically assumed that only humans are capable of this complex emotion state, recent research paints a different picture.

According to Brooks Pribac, different "attachment styles" contribute to complicated grief. Animals with an "insecure attachment style," as defined by Fraley and Shaver (2016), may have the kind of brain organization that cannot properly cope with a devastating loss. Animals who have an insecure attachment style (say, on account of being denied speciestypical upbringing) and who suffer a tragic loss (say, the loss of a lifetime companion) may experience complicated grief. This could explain why some dogs starve themselves to death after the death of their human companions (Brooks Pribac, p. 1).

Eilam agrees with Brooks Pribac on this point and cites the tragic case of Flint reported in Goodall (1996). After a female chimpanzee named Flo died, her son Flint entered a deep depression and lost the will to live. Goodall (1996) writes:

"For Flint, Flo's death was a blow from which he never recovered. It was as though, without his mother, he no longer had the will to live. Hunched and miserable, he sat on the bank of the stream near his Flo's body. From time to time he approached her, searching, it seemed, for a sign of life. He stared at her, then pulled at her hand as though begging her to groom him, to comfort him, as she had done throughout his life. But Flo's body lay motionless - cold and dead. Finally, Flint moved away. His depression worsened. He ate almost nothing, he stayed mostly alone, and in this state of grief he fell sick. We tried to help Flint in his sickness and misery. We took him food and stayed with him so that he would not feel utterly alone. But nothing helped, and about three weeks after Flo died, Flint died, too. It seems that because Flo had been too old to force the spoiled Flint to become independent, he simply couldn't face life without her" (quoted in Eilam, p. 3).

Eilam interprets Flint's inability to cope with his mother's death as a case of complicated grief analogous to the case of "dogs that have lost their human." Both cases fit under Kübler-Ross's (2007) model of grief. In both, "the depression phase is followed by an acceptance phase that represents an understanding of the finality of death. In extended grief, as reflected in endless depression, the individual remains stuck in the depression phase or even regresses to preceding phases (e.g., denial) rather than progressing toward acceptance."

Eilam and Brooks Pribac, I should clarify, are not on the same page about animal suicide. But their disagreement, I think, is essential because it throws into relief the

\footnotetext{
${ }^{23}$ Freud (1959) calls this condition "melancholia," which occurs when the patient cannot accept the sudden
} absence of a "cathexed" object and re-organize their own libidinal economy. 
importance of comparative research on negative animal emotions for people on both sides of the debate. Other negative emotions and psychopathologies that should be further studied (under ethical conditions) among animals include PTSD, normal grief, depression, schizophrenia, anguish, chronic anxiety, anhedonia, learned helplessness, and lethargy.

Work on Animal Ethics. Scientific research on animal cognition, behavior, and sentience never raises solely scientific questions. Because we regularly justify our treatment of animals based on assumptions about what animals can and cannot do, any research that challenges these assumptions will automatically have ethical ramifications. Science and ethics, therefore, stand in a dialectical relationship. Scientific discoveries influence ethical norms and ethical norms influence what constitutes acceptable scientific research. In the target article, I nod at this dialectical bond by noting that animal suicide raises uniquely ethical questions about our duties to animals: "If certain animals are shown by future research to be statistically more likely to self-destruct in certain environments, we may have a moral duty to change those environments or relocate the animals" (Peña-Guzmán 2017, p. 17).

Glymour thinks my ethical conclusions do not go far enough. If some animals really self-destruct under certain situations, we may have an obligation to not just change their environments, but to make the means for suicidal completion available to them. He grounds this provocative claim on the philosophical principle that each individual has "absolute moral authority" over its life because only the individual knows when enough is enough: "No one knows another's inner life so well as the other." And since each individual is the moral master of its own life, it would be morally wrong to force someone who has lost the will to live to go on living. To do so would be to violate their moral authority. When someone has lost the will to live and wishes to die, the right thing to do is help them realize their desire and make sure they have at their disposal the most effective and least painful means of suicide possible. ${ }^{24}$ With animals, of course, the trick is making these means available without creating a hazard for animals that may want to live since the last thing we want is to do is create lethal hazards for non-suicidal animals. Before we make lethal options available to animals, we need to know they can differentiate between lethal and non-lethal options, which is not easy to do.

Pierce also discusses ethics, but from the standpoint of animal palliative care. On her view, the target article can help us better understand, as she puts it, "who animals are as dying patients." Animals, of course, die all the time. Sometimes they die as scapegoats, sometimes as food, sometimes as subjects of pharmacological research. But sometimes they die as patients, which is to say, at the hands of a medical expert in a context of care delivery. Unfortunately, we haven't properly wrestled with the ethical quandaries of the deaths of animals. We forget that animals have an active interest in dying well and with dignity, "[that] they, too, play a role in the drama of their own passing." And because we forget this, we make unilateral decisions about how and when they die without considering their needs, wishes, and interests, even when the moral gravity of our decisions shakes us to our very core. We don't have a robust ethical framework, an animal bioethics, to deal with animals in the throes of illness and at the end of life. But we desperately need one if we want to make ethical use of what Pierce calls "the needle of oblivion." For Pierce, research on animal suicide may be a

\footnotetext{
${ }^{24}$ From the standpoint of ethical theory, Glymour's position is ambiguous. What is the status of the duty he describes? Is this a duty of justice or of benevolence? His notion of moral authority suggests that we are all moral equals in this regard and that it would be unjust (not just unkind) to deny others the capacity to commit suicide. Yet, Glymour himself describes this duty in terms of kindness rather than justice.
} 
place to start since it "has immediate and practical implications for veterinary medicine and for humans who share their lives with animals and have committed themselves, as many of us have, to seeing our companions through, all the way to the bitter end."

Philosophical Work on Animality. The debate about animal suicide is, at least in part, a philosophical debate that impacts multiple sub-branches of philosophy, including ethics (What are my duties to animals?), metaphysics (What is the nature of animal experience?), and epistemology (What can I, a human, know about a nonhuman "Other"?). In this section, I work through some of the philosophical questions raised by commentators.

Kuperus, whose focus is on the philosophical concept of temporality, brings the discussion directly to a metaphysical register. While supporting my continuist framework, he worries that the original article lacks a substantial "engagement with time." To understand whether animal suicide makes sense philosophically, we need to answer two questions about how animals experience time:

1. Do animals relate to time that has been? That is to say, do they remember the past?

2. Do animals relate to time as such? Do they know, in other words, that they are going to die?

The first of these questions has to do with memory: the second, with finitude. Let us work through them one at a time.

The issue of memory is paramount. If animals cannot remember the past - if they are "trapped in the present," to quote Nietzsche - they may be constitutionally incapable of suicide because, for Kuperus, suicide is connected to memory through trauma. Suicide involves some form of trauma or anguish, but there can be no trauma without memory since I can't suffer from what I can't remember. So, if we are going to talk about animal suicide, we need to figure out whether animals can actually remember the past and be burdened by it.

Animal cognition research suggests that many animals can. Researchers have found evidence of short-term, long-term, eidetic, and even episodic memory in species as diverse as birds, primates, and cephalopods (de Waal 2016; Dere et al. 2006; Veyrac et al. 2015), as well as evidence that some animals can be "traumatized" by their own memories of past events. A good example of this is that crows remember the humans who harmed them in the past. A better one is elephant PTSD (Bradshaw 2009). Young elephants who witness human poachers butcher their family members cannot erase these gruesome memories from their mind. These memories burden and haunt them during the day and often "return" at night in the form of nightmares and night terrors (Masson 2009), re-traumatizing the calves.

But what about Kuperus's second philosophical question? Do animals relate to what the German philosopher Martin Heidegger calls "time as such"? Do they understand, as Kuperus puts it, that time is not just "ticking," but "ticking away"? Obviously, this is not the kind of query that can be settled definitively one way or the other. Still, there are different ways to approach it, some better than others.

One way is to recast this existential question in cognitive terms and ask: What mental concepts would be required for this kind of Heideggerian anxiety? And could some animals possess them?25 At its most basic level, Heideggerian anxiety grows out of the realization that

${ }^{25}$ Heidegger would turn in his grave at the thought of reformulating the philosophy of existence in cognitivist language since he believed that "Being as such" (ontology) escapes all conceptual categories, especially those of positive science. 
I, too, will one day die. It is the realization that I am continually approaching non-existence. On a cognitivist reconstruction, two concepts seem to be involved: the concept of self and the concept of death. The synthesis of these concepts (self + death) may be what brings about that aha! moment (or, rather, ahh! moment) in which I realize that I, too, will one day die. In the target article, I showed that some animals have a concept of self, some have a concept of death, and some - e.g., nonhuman primates, some birds, and marine mammals - have both. In theory, animals in this last category could experience something akin to Heideggerian anxiety if they brought these concepts together in one thought. This, however, strikes me as a far-fetched possibility.

Thankfully, there is another way to approach the question that does not turn on believing that animals experience the kind of anxiety described by philosophers such as Kierkergaard, Heidegger, and Camus. ${ }^{26}$ On this view, which is a form of metaphysical pluralism, instead of assuming that the structures through which temporality is disclosed to living beings are the same for all species, we should embrace the possibility that temporality discloses itself differently to different species. Different animals experience time differently. Maybe elephants, octopuses, and crocodiles will never experience Heideggerian anxiety (or Beckettian absurdism or Sartrean negation or whatever), but so what? Why should their lived experience of time be subject to the same organization as ours? My inclination is to say that nonhuman animals inhabit a temporality wholly alien to us, an allotemporality that we perhaps cannot even fathom. ${ }^{27}$ To quote Berger (2009), the animal descends upon the human world "from over the horizon," from an unthinkable and utterly inhuman beyond.

\section{Concluding Remarks}

The charge of anthropomorphism is common in the field of animal studies. It is easy and powerful - too easy and too powerful, in fact. Often it is hurled carelessly and without support, even though its actual track record in the sciences is not particularly impressive. Let us not forget that this charge has historically been made, and quite violently, against scientists who challenge disciplinary dogma. Jane Goodall was viciously attacked for decades for saying chimpanzees have personalities. Donald Griffin was similarly ridiculed for saying animals have mental states. The late Jaak Panksepp reported being afraid to publish his findings on rat sociality out of fear of professional ostracism. More often than not, this charge is a tactic used to marginalize perfectly legitimate hypotheses that put pressure on received wisdom. The real threat to scientific progress, then, may not be anthropomorphism as much as what Waal (2006) calls "anthropodenial," "the a priori rejection of shared characteristics between humans and animals" (Hediger, p. 2).

\footnotetext{
${ }^{26}$ Some philosophers have argued that awareness of finitude is something that humans may not even have. Hediger argues that death is, by its very nature, unknowable. Death "is not knowable to the living," human or otherwise. It is, as Mason (2015) says, an empty and object-less concept. Since death has no object, nothing can be known about it. At most, Mason argues, we can form certain beliefs about death and speak of it metaphorically, but we can never have any knowledge of it. And neither can animals.

${ }^{27}$ Research on bird songs indicates that some birds live in a "faster" time than we do. This is why we need to slow down recordings of bird songs to appreciate the structure of some of them - because what we experience as a note (a single moment in time), they experience as an entire melody. Conversely, emerging research on plant intelligence indicates that plants live in a "slower" time. We have to speed up their behavior via time-lapse photography to understand it as purposeful and goal-directed (Lanza 2017; Pollan 2013).
} 
This is not to say that anyone who rejects the animal suicide hypothesis is necessarily an anthropodenialist, especially given that this hypothesis ultimately claims less than many critics assumed. Put bluntly, my argument was never that animals commit human suicides. Fido is not going to steal the gun, point it at his head, and pull the trigger with its paw. My argument was that we should exercise "epistemic humility" when faced with reports of animal suicide because we have reliable empirical evidence that some animals do engage in self-destructive and suicidal behaviors and good conceptual reasons to reject anthropocentric definitions of suicide.

Either way, even the staunchest of skeptics has to at some point decide what to say about mounting evidence that elbows us in the direction of animal suicide. Consider the following two reports of animal suicide cited by Eilam and Benvenuti, respectively. The first involves a monkey: the second, a bear.

"London, July 14, 1932. Sightseers at the Upton Zoo, Chester, witnessed an apparently deliberate suicide by a monkey. The monkey first gnawed through a six-feet rope hanging in his cage, tied one end to the bough of a tree, made a noose with the other end, inserted his head with great deliberation, pulled the slipknot tight, climbed the tree and jumped. Death was instantaneous. The keeper said that in a lifetime's experience he had not known an animal deliberately commit suicide.... The reason of the suicide is unknown. Had he domestic difficulties, or was he tired of life? Shocked spectators, expecting amusement, witnessed the tragedy" (Eilam, p. 2).

And,

"King (2013, 2016) relates a heart-breaking anecdote about a mother bear and her cub at the end of their lives on a bear farm in China. These farmed bears are kept horizontal in coffin-like cages for their entire lives, with a metal catheter inserted into their abdomens to harvest bile. They are allowed one unrestrained arm with which to feed themselves. It is a life so horrible that reports say the bears sometimes simply go mad and beat their heads against the bars of their cages until they die. On one mother bear, King (2013) reports: 'The cub cried out in distress as a worker prepared to harvest his bile. The mother, distressed by her loved infant's pain, broke free and squeezed the life out of her baby so that he would no longer suffer. Overcome by her own emotional pain, she ran, purposefully, headfirst into a wall, killing herself" (Benvenuti, p. 2).

Of course, skeptics can ignore these reports completely or characterize the behaviors they describe as unconnected and random motoric outputs that magically give off the impression of unity. Or, if they want to save time, they can point-blank dismiss them as "mere anecdotes."

Soper \& Shackelford opt for this path of least resistance when they assert that there is no evidence of suicidal behavior "notwithstanding countless opportunities for such self killings ... to be documented by the world's farmers, animal breeders, naturalists and scientists." But the issue is not that these reports don't exist, because they do (Ramsden \& Wilson 2014; Bekoff 2012; Palmer 2011; O'Hanlon 2010). The real issue is that scientists systematically dismiss them as "anecdotes" and neutralize them under the pretense of scientific rigor. One, of course, cannot but wonder what a report by a farmer or a breeder would have to sound like for it not to be rejected as un-scientific and anecdotal, or what a 
report by a naturalist or a scientist would have to look like for it not to be mocked as anthropomorphic. Perhaps something like this?

"At 0800 I found 14 lions of the Magadi pride at the edge of a marshy area about $20 \mathrm{~m}$ from a bull buffalo standing up to his belly in mud and water. Deep lacerations cover his muzzle and rump, his hocks are shredded, and his shoulders are full of bites, all the result of an earlier attack this morning. He faces the lions and grunts each time one moves. One lioness approaches to within $5 \mathrm{~m}$ of him but retreats when her paws get wet. At 0925 hours five nomadic males chase the pride away, then return to the buffalo at 1010 and lie 6 to $10 \mathrm{~m}$ from him. Fifteen minutes later he walks slowly toward the lions, a suicidal gesture. One male grabs his rump, another places a paw over his back and bites his shoulder. The buffalo sinks to his knees. A lion then clambers up on the lower back of the animal, bites him there and leans to one side as if attempting to turn him over. Meanwhile the other lion first licks blood off the old wounds on his shoulder, then bites there again. The buffalo bellows, yet makes no attempt to defend himself. The two males then pull him on his side, slowly, methodically without violent movements. One grabs a foreleg and turns him fully on his back. At this moment the third and fourth males join: one bites the buffalo in the throat, the other holds his nose and mouth shut with his teeth. The fifth male does nothing. One male eats the bull's testicles. After 10 minutes, at 1040, the buffalo dies" (Schaller 2009, p. 261).28

This gory account by the renowned conservationist George Schaller makes me wonder whether suicidal behaviors go under-reported in the scientific community because observers fear being labeled "anthropomorphic" by peers and colleagues - a label that, among scientists, is basically a pejorative. Maybe Schaller, an expert on a research mission, lost his mind under the blistering Tanzania sun. Or maybe he saw what he says he saw: a buffalo's suicidal gesture in a moment of crisis. How we respond to Schaller's testimony, at any rate, will always say more about us than him - or the buffalo, for that matter.

Acknowledgements: Thanks to all the commentators for their insightful comments and to the editorial team of Animal Sentience for all their support.

\section{References}

Baron-Cohen, S. (1997). Mindblindness: An essay on autism and theory of mind. Cambridge, MA: MIT Press.

Baum, W. M. (2018). What is suicide? Animal Sentience 20(18).

Bekoff, M. (2012). Did a female burro commit suicide? Psychology Today. July 22, 2012.

Benvenuti, A. (2017). Evolutionary continuity. Animal Sentience 20(4).

Berger, J. (2009). Why look at animals? In The animals reader: The essential classic and contemporary writings, Eds. Kalof, L., \& Fitzgerald, A. London, UK: Penguin Books, 251261.

Bradshaw, G. A. (2009). Elephants on the edge: What animals teach us about humanity. New Haven, CT: Yale University Press.

Brooks Pribac, T. (2017). Complicated grief. Animal Sentience 20(9).

${ }^{28}$ Thanks to Marc Bekoff for this reference. 
Brosnan, S. F. (2013). Justice-and fairness-related behaviors in nonhuman primates. Proceedings of the National Academy of Sciences, 110(Supplement 2), 10416-10423.

Brosnan, S. F., \& de Waal, F. B. (2012). Fairness in animals: Where to from here? Social Justice Research, 25, 336-351.

Damasio, A. (1995). Descartes' error: Emotion, reason, and the human brain. New York, NY: HarperCollins.

Damasio, A. (2010). Self comes to mind: Constructing the conscious brain. New York, NY: Pantheon Books.

de Waal, F. (2006). Primates and philosophers: How morality evolved. Princeton, NJ: Princeton University Press.

de Waal, F. (2010). The age of empathy: Nature's lessons for a kinder society. New York, NY: Broadway Books.

de Waal, F. (2016). Are we smart enough to know how smart animals are? New York, NY: WW Norton \& Company.

deCatanzaro, D. (2018). Roots of self-preservation failure in animal behavior. Animal Sentience 20(13).

Den Hartogh, G. (2016). Two kinds of suicide. Bioethics, 30(9), 672-680.

Dere, E., Kart-Teke, E., Huston, J. P., \& Silva, M. D. S. (2006). The case for episodic memory in animals. Neuroscience \& Biobehavioral Reviews, 30(8), 1206-1224.

Derrida, J. (2008). The animal that therefore I am. New York, NY: Fordham University Press. Durkheim, E. (2002). Suicide: A study in sociology. New York, NY: Routledge.

Dweerdt, S. (2014). Suicidal thoughts alarmingly common in people with autism. Spectrum.

Eilam, D. (2017). Animals do not commit suicide but do display behaviors that are precursors of suicide in humans. Animal Sentience 20(7).

Fraley, C. R., \& Shaver, P. R. (2016). Attachment, loss, and grief: Bowlby's views, new developments, and current controversies. In Handbook of attachment: Theory, research, and clinical applications (3rd edition), Eds. Cassidy, J., \& Shaver, P.R. New York, NY: The Guilford Press, 40-62.

Franks, D. D. (2003). Mutual interests, different lenses: Current neuroscience and symbolic interaction. Symbolic Interaction, 26(4), 613-630.

Freud, S. (1959). Mourning and melancholia. In Collected papers (Vol. 4). New York, NY: Basic Books, 152-170 (originally published in 1917).

Glock, H. J. (2010). Can animals judge? Dialectica, 64(1), 11-33.

Glymour, C. (2017). On assisted suicide. Animal Sentience 20(2).

Gómez, J. C. (1996). Non-human primate theories of (non-human primate) minds: some issues concerning the origins of mind-reading. In Theories of theories of mind, Eds. Carruthers, P., \& Smith, P. New York, NY: Cambridge University Press, 330-343.

Gómez, J. C. (2007). Pointing behaviors in apes and human infants: A balanced interpretation. Child Development, 78(3), 729-734.

Hadley, J. (2018). Post-Darwin skepticism and run-of-the-mill suicide. Animal Sentience $20(11)$.

Hediger, R. (2018). Animal suicide and "anthropodenial". Animal Sentience 20(16).

Jensvold, M. L. (2018). Lessons from chimpanzee sign language studies. Animal Sentience 20(17).

Kristeva, J. (1991). Strangers to ourselves. New York, NY: Columbia University Press.

Kuperus, G. (2018). Continuum and temporality. Animal Sentience 20(15). 
Lanza, R. (2017). Are plants aware? Psychology Today. March 11, 2017.

Leavens, D. A., Bard, K. A., \& Hopkins, W. D. (2017). The mismeasure of ape social cognition. Animal Cognition, 1-18.

Lester, D. (2017). Non-human animal suicide could be tested. Animal Sentience 20(3).

Lurz, R. W. (2011). Mindreading animals: The debate over what animals know about other minds. Cambridge, MA: MIT Press.

Masson, J. M. (2009). When elephants weep: The emotional lives of animals. New York, NY: Dell Publishing.

Mayes, S. D., Gorman, A. A., Hillwig-Garcia, J., \& Syed, E. (2013). Suicide ideation and attempts in children with autism. Research in Autism Spectrum Disorders, 7(1), 109-119.

Menninger, K. (1938). Man against himself. New York: Harcourt, Brace \& World.

Mikhalevich, I. (2018). Animal suicide: An account worth giving? Animal Sentience 20(19).

Moran, J. M., Young, L. L., Saxe, R., Lee, S. M., O'Young, D., Mavros, P., L., \& Gabrieli, J. D. (2011). Impaired theory of mind for moral judgment in high-functioning autism. Proceedings of the National Academy of Sciences, 108(7), 2688-2692.

O'Hanlon, L. (2010). Animal suicide sheds light on human behavior. NBC News. March 10, 2010.

Palmer, B. (2011). Hairy-Kiri: Do animals commit suicide? Slate. November 16, 2011.

Peña-Guzmán, D. M. (2017). Can nonhuman animals commit suicide? Animal Sentience 20(1).

Pierce, J. (2017). Understanding animal suicide and death can lead to better end-of-life care. Animal Sentience 20(6).

Pollan, M. (2013). The intelligent plant. New Yorker. December 23, 2013.

Preti, A. (2006). Suicide to harass others: Clues from mythology to understanding suicide bombing attacks. Crisis, 27(1), 22-30.

Preti, A. (2018). Animal suicide: Evolutionary continuity or anthropomorphism? Animal Sentience 20(10).

Racine, T. P. (2018). An adaptationist perspective on animal suicide. Animal Sentience 20(12).

Ramsden, E., \& Wilson, D. (2014). The suicidal animal: Science and the nature of selfdestruction. Past \& Present, 224, 201-242.

Ristau, C. A. (2017). Self, death, and suicide: Does an animal know of these? Animal Sentience 20(5).

Schaefer, H. H. (1967). Can a mouse commit suicide? In Essays in self-destruction, Ed. Shneidman, E. S. New York: Science House, 494-509.

Schaller, G. B. (2009). The Serengeti lion: A study of predator-prey relations. Chicago, IL: University of Chicago Press.

Soper, C. A., \& Shackelford, T. K. (2018). If nonhuman animals can suicide, why don't they? Animal Sentience 20(14).

Suddendorf, T., \& Busby, J. (2003). Mental time travel in animals? Trends in Cognitive Sciences, 7, 391-396.

Thomas, R. K. (2017). Is psychological science committing "suicide" by linguistic muddling? Animal Sentience 20(8).

Velasquez, M. G. (1987). Defining suicide. Issues in Law \& Medicine, 3, 37.

Veyrac, A., Allerborn, M., Gros, A., Michon, F., Raguet, L., Kenney, J., Godinot, F., Thevenet, M., Garcia, S., Messaoudi, B., Laroche, S., \& Ravel, N. (2015). Memory of occasional events in 
rats: individual episodic memory profiles, flexibility, and neural substrate. Journal of Neuroscience, 35(19), 7575-7586.

Wise, S. (2000). Rattling the cage: Toward legal rights for animals. New York, NY: Perseus Books.

Zentall, T. R. (2006). Mental time travel in animals: A challenging question. Behavioural Processes, 72, 173-183.

Zlatev, J., Madsen, E. A., Lenninger, S., Persson, T., Sayehli, S., Sonesson, G., \& van de Weijer, J. (2013). Understanding communicative intentions and semiotic vehicles by children and chimpanzees. Cognitive Development, 28(3), 312-329. 